\title{
La Messaline Française y L'Histoire de Dom Bougre, portier des Chartreux: dos ejemplos de literatura erótica
}

\author{
Claudia RUIZ GARCÍA \\ Universidad Nacional Autónoma de México
}

\begin{abstract}
En este ensayo se revisan dos novelas francesas del siglo XVIII, La Messaline Française y L'Histoire de Dom Bougre, portier des Chartreux, que ilustran algunos aspectos de la representación de la sexualidad y al mismo tiempo denuncian a las instituciones religiosas y políticas — la iglesia y la monarquía - que sustentan al antiguo régimen.

PALABRAS CLAVE: novela erótica, novela pornográfica, discurso amoroso y discurso erótico.

In this essay two French novels, La Messaline Française and L'Histoire de Dom Bougre, portier des Chartreux, of the eighteenth century are reviewed. They illustrate some aspects of the contemporary representation of sexuality, and at the same time they denounce religious institutions — church and monarchy — that support the old regime.
\end{abstract}

KEY WORDS: erotic novel, pornographic novel, erotic discourse and, love discourse.

¿Cómo abordar el tema "el erotismo en la literatura" del que se ha escrito tanto y que permite entender la postura de uno de sus especialistas, Georges Bataille, quien ha señalado en su texto De l'érotisme que el ser humano ha convertido la sexualidad en uno de sus principales problemas, si no el más importante? (277).

En este ensayo intentaremos responder a esta interrogante, revisando cómo la literatura ha representado este "problema" de la conciencia humana. Me gustaría exponer algunos aspectos de esta representación, centrándome en el siglo XVIII en Francia, por ser uno de los más documentados en esta temática y también porque en ese entonces se establece un modelo que permitirá más tarde ser recreado a través de múltiples variantes. Este modelo, recogiendo elementos de una larga tradición literaria que no puede negar, se encargará de colocar el sexo o la práctica sexual en forma discursiva para así traducir, por medio de este discurso, cómo el ser humano construye su imaginario erótico. El corpus es enorme, pero me limitaré a dos textos para de esta forma desentrañar algunas claves de esta compleja construcción.

Para facilitar esta tarea tendría que comenzar indicando que la tradición crítica ha reconocido o más bien ha opuesto dos formas de discurso sobre el sexo: la erótica y la 
pornográfica; una implícita y otra explícita, una delicada y otra brutal, una de buen gusto y otra de mal gusto, una aceptable por la censura y otra reprobable por esta instancia, y así podría continuar la lista de oposiciones, pero sería un tanto inútil, pues hoy en día la crítica ha buscado más bien diluir esas fronteras por considerarlas como arbitrarias y productos de constructos meramente culturales y por consecuencia éticos (ver Gaëtan Brulotte). Esto explicaría por qué en el pasado se consideró a Flaubert, Zola, Baudelaire o incluso a La Fontaine como autores pornográficos, lo que hoy en día ni siquiera se discutiría.

Zanjado este problema, pues meteremos en un mismo costal dos obras que podrían estar de un lado o de otro, según el ángulo por el que se les mire, interesa sobre todo acercarse a algunos aspectos que permiten establecer las diferentes variantes del modelo. Voy a referirme a novelas que no están catalogadas como obras consagradas de su tiempo y que durante más de dos siglos estuvieron purgando una pena - la del olvido - en el averno y ahora integran la famosa colección denominada "L'Enfer de la Bibliothèque Nationale", colección dirigida por Michel Camus. Ésta consta de siete voluminosos tomos, cada uno de más de trescientas páginas, que se han convertido en un referente obligado para conocer tales variantes. A lo largo de estos volúmenes se tiene acceso a novelas entretenidas, cínicas, excitantes, hipócritas, lascivas, irreverentes, a veces muy mal escritas, pero ante todo muy oportunas para revisar algunos de los aspectos de la representación del erotismo del siglo XVIII. Me refiero a L'Histoire de Dom Bougre, portier des chartreux (1741) de Gervaise de Latouche y La Messaline Française (1789) de autor anónimo.

Quisiera comenzar con L'Histoire de Dom Bougre, portier des chartreux que, a pesar de no ser la primera novela libertina de iniciación, pues tendría más bien que referirme a L'école des filles ou la Philosophie des Dames, que circula en la clandestinidad en la segunda mitad del siglo XVII, cuenta con muchos elementos comunes a ésta. Ambas pretenden modificar la visión sobre la pertinencia de acceder a la literatura erótica, al grado de convertirla en un instrumento que sirve para pensar, en esa época se diría más bien "filosofar"; es decir, participar de una de las más importantes empresas o proyectos del siglo que consistiría en aquilatar las riquezas concretas de la naturaleza. Estas novelas colocan en el centro de sus preocupaciones el erotismo, entendido como descubrimiento del cuerpo; la filosofía, como una mirada sobre el mundo, y la crítica, como el juicio u opinión sobre las costumbres sociales (Jean-Pierre Dubost: 17).

De esta forma, en L'Histoire de Dom Bougre, portier des chartreux se alterna el discurso que exalta los misterios de la naturaleza humana y aquel que denuncia los preceptos de la Iglesia y de una moral hipócrita que, a lo largo de la era cristiana, ha intentado frenar los impulsos del hombre. La novela se presenta como las memorias de un portero de la orden de los cartujos, quien, arrepentido, analiza su vida en retrospectiva y aprovecha para mostrar la más sórdida realidad bajo las apariencias y, al mismo tiempo, demostrar la hipocresía social y religiosa. Es la historia de un adolescente que descubre el placer a través de un acto de voyeurisme. Estando en su casa 
escucha un ruido en la pieza contigua y descubre, gracias a un orificio que encuentra en la pared de ese cuarto, un espectáculo sorprendente: su madre, que después sabremos que no es la madre biológica, está tendida en la cama desnuda en compañía del padre Polycarpe, director de conciencia del convento del pueblo. Ambos “juegan”, explica el protagonista, a poblar la tierra como lo hicieron nuestros primeros padres Adán y Eva. Saturnin, que es el nombre de este adolescente, nos dice:

Cette vue produisit chez moi une surprise mêlée de joie et d'un sentiment vif et délicieux qu'il m'eût été impossible d'exprimer. Je sentais que j'aurais donné tout mon sang pour être à la place du moine. Que je lui portais envie! Que son bonheur me paraissait grand! Un feu inconnu se glissait dans mes veines, j'avais le visage enflammé, mon cœur palpitait, je retenais mon haleine, et la pique de Vénus, que je pris à la main, était d'une force et d'une raideur à abattre la cloison si j'avais poussé un peu fort (L'Histoire de Dom Bougre, portier des chartreux: 14-15).

Vemos así que el primer descubrimiento de los misterios del amor pasa por una educación secreta que marca para siempre al personaje. Esta primera lección de sexología le servirá más tarde, pues iniciará a su supuesta hermana Suzon, colocándola en ese mismo agujero, para que aprenda como él lo hizo. Sin embargo, aprovecha la ocasión para potencializar el placer de ella y el suyo acariciándola, como él vio hacer al padre Polycarpe con su madre. En medio de esta entrega tan placentera para ambos, de repente producen un ruido infernal, pues el catre donde juegan a ser felices se rompe. Esto llama la atención del padre y la mujer quienes corren a ver qué ha sucedido y descubren a los adolescentes desnudos. Sorprendidos y fingiendo cierto enojo o indignación pretenden darles una lección de moral pero terminan, al ver esos cuerpos frescos y apetitosos de adolescentes primerizos, más bien saciando sus deseos con ellos. ${ }^{1}$

La figura del mirón o del voyeur, muy recurrida en esta tradición, invade varios relatos de iniciación y a veces, sobre la estructura narrativa basada en una escena de

${ }^{1}$ O Ciel! Des moments si doux devaient-ils être troublés par le plus cruel des malheurs? Je poussais avec ardeur: mon lit, ce malheureux lit, ce témoin de mes transports et de mon bonheur nous trahit: il n'était que de sangle: la cheville manqua, nous tombâmes avec un bruit affreux. Cette chute m'eût été favorable puisqu'elle m'avait fait entrer jusqu'où je pouvais aller, quoique avec une extrême douleur pour tous les deux. Suzon se faisait violence pour retenir ses cris: effrayée, elle tâchait de s'arracher de mes bras, J'étais furieux d'amour et de désespoir et je ne la serrais que plus étroitement. Mon opiniâtreté me coûta cher.

Toinette, [la madre] avertie par le bruit, accourt, ouvre, entre et nous voit. Quel spectacle pour les yeux d'une mère! La surprise la rendit immobile, et comme si elle eût été retenue par quelque chose de plus puissant que ses efforts, il semblait qu'elle ne pût avancer. Elle nous regardait avec les yeux enflammés plutôt par la lubricité que par la fureur, elle avait la bouche ouverte pour parler et la voix expirait sur les lèvres. [...] Toinette se lança sur moi au moment que je sentais les approches du plaisir, elle m'arracha des bras de ma chère Suzon. [...].

Le père Polycarpe, qui n'était pas moins curieux que Toinette de savoir ce qui venait de se passer, accourut dans cet intervalle et ne demeura pas moins surpris qu'elle à la vue du spectacle qui s'offrait à ses yeux, surtout de Suzon nue, couchée sur le dos et qui se passait un bras sur les yeux en portant la main de l'autre à l'endroit coupable, comme si une pareille posture eût pu dérober ses charmes aux regards d'un moine lascif (88-89). 
voyeurisme, en la que el personaje observa a otros en plena acción, usurpando de cierta forma un secreto, se descubrirán abusos atroces, como la de confesores u hombres que gozan de una reputación de santidad, quienes se aprovechan de jóvenes inocentes o mujeres ávidas de placer para hacerles creer que dejarse acariciar o penetrar puede llevarlas al camino de la santificación. ${ }^{2}$

Saturnino después de estas primeras y eficaces lecciones experimentará mil formas de placer con diferentes tipos de mujer, incluso de diversas clases sociales, ya que en la primera etapa de su aprendizaje llegará a completar su instrucción gracias a la colaboración de una dama de la aristocracia, mujer experimentada y libertina, Madame d'Inville, madrina de su hermana Suzon:

[...] la dame avait les yeux tournés vers moi et m'examinait. J'étais sur mon séant. Elle me passa une main sur le cou, me fit recoucher sur l'herbe et porta l'autre main à mon vit. Elle se mit à le chatouiller, à me baiser.

- Que veux-tu donc faire, grand innocent, me disait-elle? As-tu peur de me montrer un vit dont tu sais si bien te servir? Te cachai-je quelque chose, moi? Tiens, vois mes tétons, baise-les, mets cette main dans mon sein. Bon, et celle-ci, porte-la à mon con. A merveille. Ah, petit fripon, que tu me fais de plaisir!

Animé par la vivacité de ses caresses, j'y répondais avec la même ardeur. Mon doigt s'acquittait à merveille de sa fonction. Elle roulait des yeux passionnés en m'embrassant et en me poussant de profonds soupirs dans la bouche. Elle tenait ma cuisse droite passée dans les siennes et elle la serrait avec des redoublements de soupirs qu'elle termina en se laissant tomber sur moi et en me couvrant des preuves parlantes du plaisir que je venais de lui donner (115-116).

\footnotetext{
${ }^{2}$ Tal es el caso de Thérèse philosophe: texto que se inspiró en un hecho real ocurrido en 1731, referente al proceso de un jesuita, con una gran reputación de predicador y director espiritual, que abusó de una de sus penitentes que buscaba la santificación. La protagonista, Thérèse, amiga de la víctima del predicador, desde una posición de mirona, denuncia las prácticas de estos directores de conciencia que con discursos mentirosos abusan de adolescentes ingenuas. El cura le hace creer que logrará su santificación penetrándola con lo que él llama el cordón de san Francisco: «Je suis content de vous, lui dit [a su penitente] le père après un quart d'heure de cette cruelle discipline, il est temps que vous commenciez à jouir du fruit de vos saints travaux. Prosternez votre face contre terre; je vais, avec le vénérable cordon de saint François, chasser tout ce qui reste d'impur au-dedans de vous.

Le bon père la plaça en effet dans une attitude, humiliante à la vérité, mais aussi la plus commode à ses dessins. Jamais on ne l'a présenté plus beau: ses fesses étaient entrouvertes et on découvrait en entier la double route des plaisirs.

Après un instant de contemplation de la part du cafard, il humecta de salive ce qu'il appelait le cordon et, en proférant quelques paroles d'un ton qui sentait l'exorcisme d'un prête qui travaille à chasser le diable du corps d'un démoniaque, Sa Révérence commença son intromission (un episodio muy parecido se encuentra en la novela 10 de la jornada III del Decamerón de Boccaccio: "Alibech se vuelve ermitaña, a la que el monje Rústico le enseña a poner el diablo en el infierno y, al abandonar esa vida, se casa con Neerbale").

J'étais [Thérèse] placée de manière à ne pas perdre la moindre circonstance de cette scène: les fenêtres de la chambre où elle se passait faisaient face à la porte du cabinet dans lequel j'étais enfermée. Eradice [la penitente] venait d'être placée à genoux sur le plancher, les bras croisés sur le marchepied de son prie-Dieu et la tête appuyée sur ses bras. Sa chemise, soigneusement relevée jusqu'à la ceinture, me laissait voir à demi profil des fesses et une chute de reins admirables» (589, las primeras cursivas son mías).
} 
Pasajes como éstos aparecen de forma reiterada a lo largo de la novela. Si en ocasiones la realidad sexual puede ser pobre y repetitiva, la literatura debe maquillarla y presentarla con diferentes colores para evitar el aburrimiento del lector. De allí que sea importante la especificidad de cualquier encuentro. Cada uno debe realizarse en una forma y en un lugar particular, ya sea en alcobas, jardines, palacios, burdeles, incluso en lugares supuestamente ajenos a este tipo de prácticas como podrían ser los recintos sagrados. Importan en particular estos últimos porque este personaje se topará más tarde con su madre biológica, quien vive encerrada en un convento y con ella estará a punto de cometer un incesto. ${ }^{3}$ Este autor, como muchos que se reconocen en la tradición de libros prohibidos, se inclina preferentemente por representar las prácticas licenciosas de los conventos y monasterios, ya que asocia la intensidad a un exceso de privación. La abstinencia, ampliamente cuestionada por la tradición anticlerical de los siglos XVI, XVII y XVIII, se concibe más bien como una prohibición inútil, pues no hace más que exacerbar el deseo. El convento se convierte entonces en el lugar predilecto para este tipo de relatos. Durante la segunda mitad del siglo XVII y a lo largo del siglo XVIII las novelas eróticas consagran un lugar muy importante al tema de la clausura. Hacer de esta institución, regida por el voto de la castidad, el marco privilegiado de los relatos eróticos y el lugar protegido de una felicidad sensual, es una prueba contundente de un deseo de transgredir y desafiar el orden social. Gervaise de Latouche, al invertir las características del convento, lugar de coacción moral y de prohibición sexual, y transformarlo en un espacio protegido y secreto donde la mente se ilumina y los cuerpos se emancipan, está agrediendo a un símbolo sagrado de la Iglesia y por ende a sus instituciones. Resulta peligrosa esta inversión pues el libertino comienza por ser libre mentalmente al desprenderse de una serie de prejuicios y dogmas y, enseguida, se libera de las ataduras que frenan a su cuerpo (Hubert Juin: 21). Peligroso recorrido, que observaremos, aunque invertido, en la conducta de Saturnin al grado que querrá ingresar en una institución claustral para dar libre curso a sus apetitos, pues ha escuchado a uno de los padres del convento decir que fornicar, comer, reír y beber son sus principales ocupaciones. Así lo afirma cínicamente:

\footnotetext{
${ }_{3}^{3}$ J'avais déjà commencé à faire connaissance avec elle; nous avions préludé par des baisers donnés et reçus avec feu de part et d'autre, sa main avait été jusqu'à ma culotte. [...].

L'exhortation du prieur n'avait pas prévenu mes désirs, Gabrielle [la madre biológica] les avait excités. Elle se prêta galamment à les satisfaire.

—Viens, mon roi, me dit-elle, viens je veux avoir ton pucelage, viens le perdre dans un endroit où tu as reçu la vie.

Ce mot me fit trembler. Sans être devenu plus vertueux, j'avais acquis chez les moines des connaissances qui ne me permettaient pas d'être avec Gabrielle ce que j'avais été autrefois avec Toinette. J'étais prêt à enconner: un reste de honte m'arrêta sur le bord du précipice, je reculai.

—Ah, ciel! dit Gabrielle en se relevant, est-il possible que ce soit là mon fils? Ai-je pu mettre au monde un lâche tel que lui? Quoi, foutre sa mère lui fait peur!

- Ma chère Gabrielle, lui dis-je en l'embrassant, contentez-vous de mon amour; si vous n'étiez pas ma mère, je ferais mon bonheur de vous posséder, mais respectez une faiblesse qu'il me serait impossible de vaincre (185-186).
} 
J'avais conçu les idées les plus riantes de l'état monacal. Je croyais que le froc était l'habit sous lequel on eût le plus libre accès dans le temple du plaisir: mon imagination s'enivrait des chimères agréables qu'elle se forgeait. [...] Elle me représentait les plus aimables femmes... prévenant mes désirs par les attentions les plus tendres et payant ses bontés par les présents les plus vifs et les plus délicieux. On croira facilement qu'étant dans des pareilles dispositions je reçus avec joie l'habit de l'ordre, dont le Père prieur (qui s'attacha d'abord à moi avec une affectation vraiment paternelle) m'honora dès le lendemain de mon arrivée (162, las cursivas son mías).

No es gratuito que el título de la novela lleve el nombre en francés Don Bougre/Don Disoluto, Don Diablo, ya que este término se asocia con "herético" y "sodomita", pues en esa época se acusaba a los heréticos de desórdenes infames, en particular de la sodomía, que se castigaba con la pena de morir quemado en la hoguera. En uno de los pasajes de la novela Saturnin instruye a Suzon y compara el sexo del hombre con Dios, ${ }^{4}$ y Monique, una religiosa, asocia el semen con el agua bendita. ${ }^{5}$ Se trata de comparaciones muy comunes que aparecen continuamente en los textos de la época, pero también se recurre al empleo reiterado del eufemismo, la lítote y las perífrasis, que ocuparán un lugar muy importante en estos relatos, a veces incluso con tintes un tanto retorcidos o paradójicos. Si estas figuras tienen como función proteger el pudor del que lee o escucha, en realidad veremos que lo compromete desviando de su sentido expresiones inocentes e invitando al receptor a leer o decodificar en otra dirección. Cuando Saturnin nos dice que al ingresar al convento fue "honrado" por el padre prior, si en esta parte un lector descuidado no sabe desentrañar lo que el autor nos quiso decir con esta sutileza, más tarde, cuando el personaje narrador ya no se autonombra Saturnin, sino "Dom Bougre/Don Disoluto", nos dice de forma clara y directa muchas cosas. Asumido ya como un libertino encarnizado explica cómo acepta ser sodomizado y más tarde él mismo se erige en un sodomita por excelencia. Incluso relata el discurso de un padre de la orden a la que pertenece en el que se hace la apología de esta práctica, considerada por la Iglesia como totalmente antinatural. Sorprende que en boca de éste escuchemos al padre Casimiro hacer una lista de los "bougres/los disolutos/los heréticos" más renombrados de la historia desde Adán hasta la creación de la orden de los jesuitas, señalando a filósofos, papas, emperadores y cardenales: elogiando a cada uno de ellos y condenando la injusticia y ceguera de aquellos que se oponen a este placer, practicado por hombres tan respetuosos, genios de la humanidad, remontándose hasta los episodios de Sodoma, agregando que por celos se había falsificado este memorable episodio.

\footnotetext{
${ }^{4}$ Un vit, ma chère Suzon, est le membre d'un homme; on l'appelle le membre par excellence parce qu'il est le roi de tous les autres. Ah! Qu'il mérite bien le nom! Mais si les femmes lui rendaient la justice qu'il mérite, elles l'appelleraient leur Dieu. Oui, c'en est un. Le con est son domaine, le plaisir est son élément, il va le chercher dans les replis les plus cachés, il pénètre, il sonde, il le trouve, il s'y plonge, il le goûte, il le fait goûter, il y naît, il y vit, il y meurt et renaît pour le goûter encore (48-49, las cursivas son mías).

${ }^{5}$ Il est temps de t'apprendre ce que c'était cette eau bénite dont le père Jérôme t'arrosa un jour la gorge en te donnant l'absolution (63).
} 
En suma, padres y monjas se entregan a orgías conventuales, y así nuestro personaje Saturnin, viviendo en el convento donde está recluida la monja Gabrielle, descubre en ella, como ya se dijo, a su verdadera madre, aunque no logra reconocer a su verdadero padre, pues deduce, al observar las prácticas comunes de estos espacios cerrados, que en el convento todos contribuyeron con un granito de arena en el acto amoroso de su concepción y termina diciendo que es "le fruit de l'incontinence des Révérends Pères Célestins de la ville de R... Je dis des Révérends Pères, parce que tous se vantaient d'avoir fourni à la composition de mon individu" (11-12). Don Disoluto sale del convento, llega a París y allí se encuentra a su supuesta hermana Suzon, quien se dedica a la prostitución. Ella le trasmite la sífilis, razón por la cual más tarde será castrado. Finaliza esta historia con una desgastada estrategia que muestra el discurso del arrepentimiento. Quizá por esta convención tramposa se explique el hecho de que un conocido eclesiástico, el abad Nourry, haya sido uno de los principales promotores de esta novela, pues se sabe que se encargó de vender en la clandestinidad algunos ejemplares (Pascal Pia: 221).

Si en el caso de L'Histoire de Dom Bougre, portier des chartreux se cuestionaba ferozmente a la Iglesia a través de la disciplina que impera al interior de sus instituciones, en La Messaline française se ataca a otro gran pilar en el que descansa la sociedad del antiguo régimen: la monarquía. En esta ocasión se trata de la reina María Antonieta, esposa de Luis XVI. El título del texto se explica por las palabras proferidas por un juez encargado del proceso del tribunal revolucionario contra esta reina en el que se le acusó de todos los desórdenes sexuales tales como furores uterinos y lesbianismo, incluso el abuso sexual de su propio hijo, el que nunca ocuparía el trono de Francia (Michel Camus, estudio introductorio: 9-11). Se le asoció con el famoso personaje de la historia romana, la esposa del emperador Claudio (Mesalina), conocida por sus inclinaciones ninfómanas. A María Antonieta se le denominó públicamente como "la madre de todos los vicios" y fue el blanco de miles de panfletos, canciones populares, falsas memorias y novelas eróticas, donde se le mostró ya fuera como una figura política capaz de participar en indignos complots contra el pueblo francés, así como una mujer con una sexualidad desenfrenada. ${ }^{6} \mathrm{Al}$ inicio del texto se anuncia: "je vais te dévoiler mes intrigues avec une femme altière, aussi honteusement célèbre par ses prostitutions que par ses horribles complots contre le peuple français" (La Messaline française: 299 ).

\footnotetext{
${ }^{6}$ Entre los textos más importantes que intentaron destruir la imagen de la reina, cabe citar: Les nuits de Marie-Antoinette, Les passe-temps d'Antoinette, L'Autrichienne en goguette, Le Godemiché royal, Bordel national, sous les auspices de la reine, Soirées amoureuses du général Mottier et de la belle Antoinette, Fureurs utérines de Marie-Antoinette, femme de Louis XVI y Jugement général de toutes les putains françaises et de la reine des garces, par un des envoyés du Père éternel, entre muchos otros (ver Jean-Jacques Pauvert).
} 
Se trata, ${ }^{7}$ como en Dom Bougre, de un relato en retrospectiva escrito en primera persona donde la voz narrativa advierte desde las primeras líneas el tono del mismo. Así, dirigiéndose a su posible lector, le dice: "Mon ami, tu ne verras ici que les scènes les plus licencieuses, les tableaux du libertinage le plus effréné, et mon style sera tel qu'il convient pour peindre une Messaline qui laisse loin derrière elle les courtisanes les plus débordées" (299). Este texto crea la ilusión, desde la primera página, de que lo escribe un joven abad que intenta preservar su identidad y la de las protagonistas; es decir, la reina, una princesa y la duquesa de Polignac, al recurrir al efecto retórico del empleo de iniciales para designar a tres personalidades públicas con la supuesta e hipócrita intención de no comprometerlas. El relato es muy simple, pues este joven abad se limita a contar cómo, después de un encuentro casual con una princesa, en la Corte de Versalles, se topa con una desconocida que posee una belleza voluptuosa y se entrega a ella con tal entusiasmo que, nos dice, lo transporta al séptimo cielo. Antes de separarse, esta mujer misteriosa le ofrece una pequeña fortuna de alrededor de cincuenta mil libras. ${ }^{8}$ La relación dura casi seis meses. Más tarde, una dama de honor lo introduce en un oscuro aposento del castillo de Versalles. Después de varios momentos de gozo intenso, creyendo haber estado con su amante, al levantar la cortina de la ventana, descubre que acaba de hacer el amor con la duquesa de Polignac, quien le da a entender que esa dama misteriosa que ha poseído varias veces y que tanto le intriga es la reina de Francia, María Antonieta. Este relato breve, y muy pobre en aventuras, se limita únicamente a describir los diferentes encuentros amorosos. En ellos el lector se enfrenta a una serie de escenas, recursos y léxico que pertenecen a la tradición del relato galante y que se irá transformando e inclinando hacia el tono de la transgresión. En su primera reunión en el boudoir, al descubrir el cuerpo desnudo de una de sus amantes tendida sobre la cama durmiendo, nos dice:

Quel spectacle enchanteur s'offre à mes regards!... Mon adorable... dormant étendue sur un lit de repos, dans l'attitude la plus voluptueuse, la gorge nue, une jambe élevée, l'autre pendant à terre, les cuisses les plus blanches écartées et, par la posture où elle se trouvait, absolument découvertes... J'entrevoyais le centre des plaisirs, ombragé d'une mousse épaisse, dont la couleur contrastait admirablement avec l'albâtre de sa peau immobile. J'ose à peine respirer, des torrents de feu circulent dans mes veines. J'avance sur la pointe du pied, je me mets à ses genoux, j'admire tout ce que la nature forma jamais de plus beau... J'ose appliquer mes lèvres..., mais je crains de la réveiller et de perdre une si belle occasion. Ma timidité disparaît: je me relève et, monté sur le lit de repos, je m'établis entre ses cuisses avec la plus grande précaution.

\footnotetext{
${ }^{7} \mathrm{Al}$ igual que L'École des filles y L'Histoire de Dom Bougre el relato se presenta desde la portada como una novela de aprendizaje: "Ouvrage fort utile à tous les jeunes gens qui voudront faire un cours de libertinage!"

${ }^{8}$ Lorsque je fus dans ma chambre, je voulus voir ce que contenait le portefeuille qu'elle m'avait donné. Conçois mon étonnement... il était enrichi de diamants pour près de vingt mille libres. Le bouton qui servait à l'ouvrir valait seul plus de huit mille libres. Il renfermait trente billets de la caisse, de mille libres chaque. Quel magnifique présent! Je ne pouvais en croire mes yeux (312).
} 
J'applique ma bouche contre la sienne, je pénètre dans l'antre sacré de la volupté (301).

Así, se empieza por nombrar lo que en ciertos sectores de la sociedad era innombrable. Se recurre al empleo de perífrasis que pretenden proteger los ojos o los oídos del lector, pero a menudo esta estrategia sólo sirve para exacerbar su indignación pues se hace uso del léxico religioso para referirse a los órganos sexuales. Al masculino se le denomina a veces "la reliquia" y al femenino "el antro sagrado", "el altar" o la "sala del dios omnipotente". Para la erección se hablará de "la resurrección de la carne". 9 Se empleará el juramento para traducir la intensidad de las sensaciones tales como “¡Dios santo!”, “¡Dios todopoderoso!”, “¡Virgen santísima!”, “¡Arcángeles celestiales!”, etcétera. El placer resentido por los personajes se verbaliza por medio de una serie de convenciones que tratan de reproducir las marcas de la perturbación emotiva como sería la aparición reiterada de exclamaciones tipo “¡Oh!”, “¡Ah”! o la fragmentación léxica. El abad, al referir el primer encuentro amoroso con la duquesa, nos dice:

[...] elle veut parler et je lui ferme la bouche par un baiser. Cependant une chose m'étonne. Elle a l'air de vouloir se dérober à mes caresses. Je la retiens dans mes bras, ma langue caresse voluptueusement la sienne, mon doigt s'empare du siège du plaisir, déjà je sens son clitoris se gonfler dessous. Ces titillations précipitées attirent vers cette partie tous les esprits libidineux. Je fais circuler dans ses veines le plaisir à grands flots, ses cuises, qu'elle avait serrées, s'écartent peu à peu, un léger mouvement de ses fesses m'annonce qu'il est temps d'agir plus sérieusement. Je m'entends sur elle et je pénètre avec vigueur dans la place. Mais, ô dieux, quels sont les transports de mon amante! Elle se livre à mes caresses avec fureur, elle suce, elle mord toutes les parties de mon corps auxquelles sa bouche peut atteindre. L'excès du plaisir l'emporte... Elle ne se connaît plus. Fortement serrée dans mes bras, ses jambes entrelacées sur moi, nos deux corps n'en forment plus qu'un. Quelle précipitation! quelle agilité dans les mouvements!... Mais ils redoublent encore, ce ne sont plus que des soupirs entrecoupés... Je sens moi-même que les sources de la suprême volupté sont prêtes à s'ouvrir. Tous deux ensemble joignons le but...

—Ah!... cher... che... valier... que je t'aime... mon âme... tu me tues... va... va... oh!... c'en est... trop... je... meurs... (314-315). ${ }^{10}$

\footnotetext{
${ }^{9}$ Esta expresión aparece en la novela 10 de la jornada III del Decamerón de Boccaccio: "Alibech se vuelve ermitaña, a la que el monje Rústico le enseña a poner el diablo en el infierno y al abandonar esa vida, se casa con Neerbale".

${ }^{10}$ Un encuentro amoroso con la reina es descrito casi con los mismos términos: "Pourrai-je jamais t'exprimer la blancheur, le satiné de sa peau, cette gorge divine sur laquelle sont posés deux jolis boutons de rose, l'élégance, la souplesse de sa taille, le contour, la fermeté de deux fesses dont la partie supérieure forme la chute de reins la plus admirable, la rondeur de deux cuisses que jamais l'art ne pourra imiter? Pourrais-je te peindre ce ventre lisse et poli sur lequel j'imprimai un million de baisers?... Pourrai-je, surtout, te donner une idée de ce réduit admirable, le plus bel ouvrage de la nature, centre de tous nos plaisirs, lieu délicieux où l'amour a fixé son séjour? Vit-on jamais une motte mieux relevée et garnie d'une plus jolie mousse?... Mes mains heureuses parcourent en détail toutes ces beautés, ma bouche se colle sur toutes les parties de ce beau corps. Bientôt, entraîné par mes transports, je me précipite sur elle, j'entrouvre d'un doigt
} 
Estas marcas de puntuación pretenden autentificar el juego escénico y dramatizar el gozo; es decir, teatralizar su propio medio de enunciación. Con ello se intenta comunicar el placer al otro. El "orgasmo", palabra que nunca aparece de forma explícita, pues aunque existe en el diccionario se refiere a un "acceso de cólera" y sólo será utilizada para designar el punto más alto del placer sexual a partir de 1837 (Trésor de la Langue Française), se nombra de otra forma, ya sea por sonidos mal articulados, por interrupciones del discurso, como lo hemos visto en el ejemplo citado y, finalmente, por el silencio de la voz narrativa que se presenta por el famoso espacio en blanco sobre la página.

Si en el caso de Dom Bougre el personaje participa de orgías conventuales que llenan páginas y páginas y sirven para hacer avanzar el relato, en la Messaline française se utilizan varios elementos del texto erótico modelo, pero en menores cantidades. Aquí también se recurre a la convencional estrategia del voyeurisme, pues el personaje descubrirá a través de una cerradura a la duquesa hacer el amor con su dama de honor, una joven apetitosa de dieciocho años y, motivado por tal espectáculo, entrará en la habitación y participará de los juegos amorosos. Sin embargo, comparado con el texto anterior, La Messaline es una novela muy pobre que ha interesado a la crítica literaria únicamente, ya que presenta a una de las figuras del poder, la reina, en una posición "incómoda" o si se quiere de alguna forma "degradada", pues el relato la presenta presa de sus apetitos lúbricos y lista a pagar cualquier suma para procurarse este tipo de placeres "voluptuosos", inclinación atribuida constantemente a María Antonieta, sobre quien se escribieron miles de novelas y panfletos que recogían los rumores de los deseos insaciables de esta soberana odiada por los franceses por ser extranjera, austriaca, y a quien se le responsabilizó, en una primera etapa, sobre la supuesta impotencia sexual del rey Luis XVI. Jean M. Goulemot, en el estudio introductorio de la edición de Fayard, reconoce que los alcances de la materia del texto, en un sentido político (antimonárquica y antiaristocrático), son menores. Sin embargo, afirma: "on ne peut ignorer que les pamphlets antiprotestants, anticatholiques, ou dirigés contre les financiers, et, à la veille de la Révolution, contre la Cour et plus spécialement contre la reine, pour ne citer que ces exemples, ont très largement utilisé l'accusation sexuelle pour mieux discréditer leurs adversaires" (292).

léger le séjour du dieu puissant qui m'anime. J'y introduis le trait brûlant dont il m'a orné... Je l'enfonce avec une espèce de fureur, mes secousses sont précipitées... Déjà mon amante ne pousse plus que des soupirs entrecoupés. Se jambes, croisées sur mes reins, m'attirent avec force vers elle. Elle semble craindre que je ne lui échappe. Ses mouvements répondent aux miens. Déjà s'approche l'instant marqué par la volupté, instant qui, s'il durait, nous rendrait supérieurs aux dieux. Déjà jaillissent les sources du plaisir. «Ah... Dieu! ...Ah... Chère!... Cher amant!... Va!... Oh va... fort... quel... plaisir!... Ah!... ah!... j'ex... pire...» sont les seuls monosyllabes que nous pouvons prononcer. Nous tombons enfin dans une prostration de forces des plus complètes. Notre anéantissement est à son comble... et nous ne renaissons quelques instants après que pour nous replonger de nouveau dans la même ivresse voluptueuse. Notre excessif affaiblissement mit seul fin à nos transports" (310-311). 
Con este tipo de textos se asiste al desmantelamiento de los dos grandes pilares del antiguo régimen, la Iglesia y la monarquía, y se cuestiona el valor del origen cristiano que se le ha conferido al matrimonio en detrimento del amor, del deseo, del gozo o del placer. Los personajes se entregan a él rompiendo las barreras religiosas, morales y sociales. Resulta interesante escuchar a la religiosa Monique instruir a Suzon:

Nous ne sommes pas maîtresses des mouvements de notre cœur: séduites dès la naissance par l'attrait du plaisir, c'est à lui que nous offrons nos premiers sentiments... Des vieilles que l'âge les a rendues insensibles au plaisir, ou plutôt que la retraite leur interdit, croient se dédommager de l'impuissance de le goûter, par le portrait hideux qu'elles nous en font. Laissons-les dire Suzon! Quand on est jeune on ne doit avoir d'autre maître que son cœur, ce n'est que lui qu'il faut écouter, ce n'est qu'à ses conseils qu'il faut se rendre (41).

Por su parte, el padre prior le explicará a Saturnin que no cree en esas mentes mediocres y enfermas a quienes la sexualidad les escandaliza. Le recuerda que el acto sexual es tan natural como el de comer y beber, y agrega "nous sommes moines, mais on ne nous coupe ne le vit ni les couilles quand nous entrons dans le cloître" (178), y otro monje le dirá que la "fouterie sans distinction est d'institution divine" y parafraseando la conocida recomendación de san Pablo, "mejor casarse que quemarse", agregará "Plutôt que de brûler, foutez mes enfants, foutez" (188). De esta forma, se exalta la idea de la felicidad terrenal y no celestial. Visión ampliamente explicada en el siglo por uno de sus filósofos más incomprendidos, La Mettrie, quien afirmaba en su Discours sur le bonheur: "De toutes les espèces de bonheur, je préfère celle qui se développe avec nos organes, et semble se trouver, comme la force, dans tous les corps animés" (247).

En este siglo, en el que el saber es una de las condiciones para acceder a la felicidad, estos relatos la conciben únicamente bajo la perspectiva de la sensación y del placer que conlleva a una especie de iluminación. El conocimiento está ligado al gozo que puede prolongarse según los espacios y las formas. Interesante transformación en la historia de las mentalidades que permite crear una diferencia, aunque un tanto arbitraria pero cómoda, en la manera de definir el discurso amoroso. A éste se le reconoce en la tradición occidental como aquel que se nutre de lo imposible, de la ausencia, de la privación y del sufrimiento, mientras que el discurso erótico se le concibe como el relato de la entrega, la presencia y la repetición, concluyendo en la saciedad completa del deseo. Robert Muchembled explica en L'orgasme et l'occident. Une histoire du plaisir du XVIe siècle à nos jours, que para entender la importancia de la mutación erótica del siglo XVIII es indispensable mirar la invasión o proliferación de este tipo de discurso literario. Al mismo tiempo que atacó a la Iglesia y al Estado, se orientó a partir de entonces hacia un rechazo categórico de una sexualidad demasiado controlada por estas instancias y exaltó el alcance de la ciencia y de la filosofía natural para concebir el cuerpo a partir de ángulos ajenos al concepto de pecado (163-165). Este discurso, difícil de cuantificar en el siglo, resulta de gran interés para entender el cambio 
de paradigma de nociones tales como 'felicidad', 'cuerpo', 'libertad', 'naturaleza', 'vicio', 'virtud'... entre otras tantas.

\section{Obras citadas}

BATAILlE, Georges. L'Érotisme. París: Les Éditions de Minuit, 1957-2011. Impreso. BocCACCIO, Giovanni. El Decamerón. Barcelona: Mandri, 1976. Impreso.

Brulotte, Gaëtan. Euvres de Chair. Figures du discours érotique. Quebec: L'Harmatan, les Presses de l'Université Laval, 1998. Impreso.

Dictionnaire des Euvres Erotiques. Domaine Français. Est. introd. Pascal PíA. París: Mercure de France, 1971. Impreso.

Dictionnaire Trésor de la Langue Française. Web.

La Messaline française. Est. introd. Michel CAMus. París: Gallimard, 1999. Impreso.

La MetTrie, Julien Offray de. Discours sur le bonheur en Corpus des auvres de philosophie en langue française. París: Fayard, 1987. Impreso.

LATOuCHE, Gervaise de. Histoire de Dom Bougre, portier des chartreux. Arles: Actes Sud, 1993. Impreso.

Muchembled, Robert. L'orgasme \& l'occident. Une histoire du plaisir du XVIe siècle à nos jours. París: Seuil, 2005. Impreso.

Euvres anonymes du XVIIIe I. Est. introd. Michel CAMUS y Hubert JuIN. París: Fayard, 1985. Impreso.

Euvres anonymes du XVIIIe III. Est. introd. Michel CAMUS y Jean M. Goulemot. París: Fayard, 1986. Impreso.

Euvres érotiques du XVIIe siècle. Est. introd. Jean DuBost y Michel CAMUS. París: Fayard, 1988. Impreso.

PAUVERT, Jean-Jacques. Anthologie historique des lectures érotiques de Gilgamesh à Saint Just de -2000 à 1790. París: Stock / Spengler, 1995. Impreso.

Romans libertins du XVIIIe siècle. Thérèse Philosophe. Bruselas: Robert Lafont, 1993. Impreso. 